\title{
El personaje campesino en Aristófanes y su acción ético-política*
}

\author{
Carlos Andrés Gallego Arroyave**
}

Recibido: 28 de julio de 2016 - Aprobado: 26 de septiembre de 2016

\section{Besumen}

El campesino ateniense, como sujeto histórico y, también, como personaje del teatro cómico de Aristófanes, fue figura central y esencial en el transcurso del siglo $\mathrm{V}$ a. C., dado que su postura ético-social permaneció intacta y óptima frente a los padecimientos bélicos de Atenas, por lo cual tomó un carácter de idealización tanto en su posición de ciudadano como en las personificaciones de la comedia aristofánica. Este artículo analiza la manera como Aristófanes configura en el hombre rural el sujeto idealmente ético y político que necesita la polis ateniense para reconstruirse y transformarse. Esta percepción del campesino en Aristófanes otorga una ilación con los sucesos tanto del ciudadano como de la ciudad, y le brinda al lector una lectura histórica distinta de los eventos que padeció Atenas durante la guerra del Peloponeso.

Palabras clave: Aristófanes, campesino, polis, ética, filosofía antigua

Artículo de reflexión inserto al proyecto Figuras de lo Otro en la Tragedia y Comedia Griega (Rad. 45734), del semillero de investigación Estudios Antiguos, vinculado al grupo de investigación Filosofía y Teología Crítica de la Universidad Católica Luis Amigó (Medellín). DOI: http://dx.doi.org/10.15332/s0120-8454.2017.0090.09

Profesional en Filosofía de la Universidad Católica Luis Amigó (Medellín). Miembro e investigador principal del semillero de investigación Estudios Antiguos. Dirección postal: Calle 36 \# 52-04, int. 1403, Bello, Antioquia. Correo electrónico: carlos.gallegoar@gmail.com 


\title{
The peasant character in Aristophanes and his ethical-political action*
}

\author{
Carlos Andrés Gallego Arroyave**
}

\section{Abstract}

The Athenian peasant, as an historical subject and, also, as a character of Aristophanes comic theater, was a central figure during the V century b. C., as their ethic and social position remained intact and optimal against the Athens warlike sufferings. Due to these reasons, the character was idealized both in position of a citizen and in personifications of the aristophanic comedy. This article analyzes the way in which Aristophanes set in the rural man the ethical and political ideal subject needed by the Athenian polis to be reconstructed and transformed. Aristophanes' perception of the peasant provides a connection with the events, both the citizen and the city, and a different reading of the events suffered by Athens during the Peloponesian war.

Keywords: Aristophanes, farmer, polis, ethic, ancient philosophy.

Reflection article inserted in the project Figures of the Other in the Greek Tragedy and Comedy (Rad. 45734), from the research seedbed Antique Studies, attached to the research group Philosophy and Critical Theology of the Catholic University Luis Amigó (Medellín). DOI: http://dx.doi.org/10.15332/s0120-8454.2017.0090.09

* Professional in Philosophy from the Catholic University Luis Amigó (Medellín). Member and principal investigator of the research seedbed Antique Studies. Postal address: Calle 36 \# 52-04, int. 1403, Bello, Antioquia. Email: carlos.gallegoar@ gmail.com 


\title{
Le personnage paysan chez Aristophane et son action éthico - politique*
}

\author{
Carlos Andrés Gallego Arroyave ${ }^{* *}$
}

\section{Résumé}

Le paysan athénien, comme sujet historique et, aussi, comme personnage du théâtre comique d'Aristophane, a été une figure centrale et essentielle au cours du Ve siècle av. J.-C., étant donné que sa posture éthico - sociale est restée intacte et parfaite face aux souffrances belliqueuses d'Athènes, raison pour laquelle il a pris un caractère d'idéalisation aussi bien dans sa position de citoyen comme dans les personnifications de la comédie d'Aristophane. Cet article explique comment Aristophane configure chez l'homme rural le sujet idéalement éthique et politique, qui a besoin de la polis athénienne pour se reconstruire et se transformer. Cette perception du paysan chez Aristophane octroie un enchaînement avec les événements du citoyen et de la ville, et offre au lecteur une lecture historique différente des évènements subi par Athènes durant la guerre du Péloponnèse.

Mots clés: Aristophane, paysan, polis, éthique, philosophie antique.

Article de réflexion lié au projet Figures de l'Autre dans la Tragédie et la Comédie Grecque (Rad. 45734), du groupe de recherche Études Antiques, lié au groupe de recherche Philosophie et Théologie Critique de l'Université Catholique Luis Amigó (Medellin). DOI: http://dx.doi.org/10.15332/s0120-8454.2017.0090.09

* Professionnel en Philosophie de l'Université Catholique Luis Amigó (Medellin). Membre et chercheur principal de la pépinière de recherche Études Antiques. Adresse postale: Calle 36 \# 52-04, int. 1403, Bello, Antioquia. Email: carlos. gallegoar@gmail.com 


\section{Introducción}

El surgimiento de la ciudad (polis) fue la constitución decisiva para las transformaciones sociales, políticas, intelectuales y artísticas de los habitantes de la Atenas clásica. El advenimiento de la polis marcó un comienzo al determinar la vida social del hombre y su relación con las instituciones, especialmente para el campesino (georgós), quien pudo, con el proceso del sinecismo y la consolidación del proyecto democrático, realizar acciones políticas dentro del ámbito civil. Sin embargo, durante el siglo $\mathrm{V}$, hubo un acontecimiento que produjo un cambio significativo en Atenas y en la vida cotidiana del ciudadano (polites), a lo que se añade, además, la afectación en el campo económico, político y militar. Sin duda, este acontecimiento fue la guerra de Peloponeso, un enfrentamiento iniciado en el 431 a. C., que provocó un cambio abrupto colectivo, producto de los intereses políticos y privados por parte de las dos ligas enfrentadas: la liga de Delos (conducida por Atenas) y la liga del Peloponeso (guiada por Esparta).

El fortalecimiento institucional de Atenas en el trascurso de la primera mitad del siglo $\mathrm{V}$, su prosperidad y su tendencia imperialista para con los demás aliados de la liga délica desencadenó un recelo en Esparta; tanta fue la inquietud, que los mismos espartanos pidieron a Atenas, de manera diplomática, abandonar la visión expansionista y la opresión económica hacia los aliados ático-délicos. Esta petición fue rechazada por Atenas que, en consecuencia, llevó a la liga peloponesia a atacar por intercesión de aquellos aliados ${ }^{1}$.

La guerra del Peloponeso fue para los habitantes helénicos un suceso temible que originó una crisis irreversible. Esta decadencia se vio reflejada principalmente en la ilustración ateniense donde las letras y artes (teatro, filosofía, escultura, poesía, oratoria, etc.) comenzaron a asistir y reflejar una debilitación social, ética y política en la ciudad. Con Eurípides se logró apreciar un declive en las acciones morales de los ciudadanos y gobernantes, a causa de los excesos e imprudencias de estos; el trágico le otorga virtudes al ciudadano-campesino (georgós) posicionándolo, dentro de la tragedia, como el ciudadano democrático ideal. Si bien Eurípides brinda un crítica a los actos bélicos y políticos de la época, quien más representa con sus obras rechazo y crítica a la crisis socio-política de Atenas causada por la guerra es el cómico Aristófanes, un hombre que con su poesía acusó directamente a aquellos gobernantes y estrategas que solo planeaban la victoria de Atenas contra Esparta a cualquier costo. Su feroz crítica no se dirigió solamente hacia los gobernantes: Aristófanes también señaló a los habitantes de la ciudad, dado que siguieron aceptando las adulaciones de los demagogos mientras apreciaban el deterioro estructural y moral de la polis. No cabe duda que la poesía cómica de Aristófanes da al espectador un momento

1 La profesora Julieta Pérez Monroy expresa ampliamente los antecedentes que ocasionaron la guerra del Peloponeso, y afirma que hubo negligencia en ambas ligas, referente a distintas peticiones que estas mismas estaban solicitando, dado que los laconios pedían la liberación de los aliados sometidos por la liga délica; los atenienses, instigados por Pericles, respondieron con la misma petición que los espartanos hicieron con los suyos, pero la gestión no tuvo éxito, ya que ninguna liga cedió. Por lo tanto, "los sucesos se precipitaron cuando un grupo de tebano atacó sorpresivamente la ciudad de Platea, aliada de Atenas. De esta forma, las treguas quedaron rotas definitivamente y se inició la guerra (431 a. C.)" (1996, p. 50) 
de relajación, sin embargo también presenta explícitamente la problemática que afecta a Atenas, de este modo lo introduce Pérez Monroy (1997):

Asimismo, debemos tomar en cuenta que, aunque el propósito de la comedia es provocar la risa del público, las acciones señalan problemas reales y serios de la polis y, a pesar de que siempre se presenta un final feliz y fantástico, la intención del autor es incitar a la búsqueda de soluciones (pp. 12-13).

Luego del proceso del sinecismo y la vinculación que hubo con la vida cívica y política, el ciudadano-campesino llevó una vida tranquila, de relativa comodidad y sin muchas complicaciones; con la producción de alimentos en la aldea (kóme), el hombre rural podía sostenerse económicamente, la vida social y religiosa se llevaba sin ningún apuro, y aún sostenían sus prácticas culturales y sagradas desde la época hesiódica. La vida campesina que se llevaba antes de la guerra era por ciclos, y cada uno de estos acondicionaba una actividad, principalmente la labranza, que era la acción predominante en la aldea. El campesino, con la ayuda de un esclavo, se esforzaba en la siembra de su tierra, con el fin de producir una buena cosecha. Un personaje aristofánico de la obra Acarnienses resume esta labor de cultivar y cosechar los productos más abundantes del Ática:

Pero, si te agarrara, creo que aún te echaría... tres cosas: primero plantaría una larga hilera de cepas recientes; luego, retoños nuevos de higuera junto a ella, y en tercer lugar, un vástago de parra; sí, yo, este viejo, y en torno a la finca pondría a la redonda olivos, para ungimos con su producto tú y yo en las lunas nuevas. (Ar. Ach. 994-999)²

Además del cultivo, el georgós también criaba animales para dos aspectos: el primero se proporcionaba para la alimentación de su hogar (oikos), una complementación de la dieta con carne, huevos y leche; el segundo aspecto se brinda con el fin de satisfacer necesidades laborales, es decir que algunos animales servían para el arado de la tierra (Pérez Monroy, 1997, p. 14). Sin embargo, para el labrador la labranza no lo era todo, también habían épocas en las que los integrantes de la aldea se reunían para realizar banquetes y prácticas religiosas, estas iban muy ligadas, dado que posibilitaban vínculos entre los oikos que fortalecían la camaradería (Gallego, 2003). También hay que considerar que estas festividades religiosas les brindaban al campesino un acercamiento a Perséfone y Deméter, diosas de la agricultura, para obtener una excelente cosecha ${ }^{3}$.

Sin embargo, la comodidad y vida próspera que llevaban los campesinos (georgoi) en su aldea se vio interrumpida por la guerra del Peloponeso. El propio Tucídides

2 Las abreviaturas de los autores y obras griegas empleadas en este artículo están sujetas al método de referencia de Henry George Liddell y de Robert Scott, que aparece en la obra A Greek English Lexicon.

3 Estos rituales ofrecidos a Perséfone y Deméter que realizaban los campesinos durante sus fiestas, y antes del inicio de la temporada de cultivos, se evidencia primero en Hesíodo: "[T]ú recuerda siempre nuestro encargo y trabaja, Perses, estirpe de dioses, para que te aborrezca el Hambre y te quiera la venerable Deméter de hermosa corona y llene de alimento tu cabaña" (Hes. Op. 296-300). Posteriormente, en el siglo V, Aristófanes hará en Tesmoforias una veneración con contenido más sagrado a Deméter: "Pedid a las dos tesmóforos y a Pluto y a Deméter propiciadora de hermosas cosechas" (Ar. Th., 2007, pp. 298-299). 
expresa en su Historia el malestar que pasaron los aldeanos luego de que Pericles decidiera llevárselos a los Muros Largos, es decir, a la zona urbana de Atenas ${ }^{4}$. Ese rompimiento de vínculo con la vida tradicional rural que padecería el aldeano desataría, como lo justifican Austin y Vidal-Naquet (1986), el "abandono del ideal del campesino-ciudadano" (1986, p. 147). A partir de aquel momento en que estalló la guerra y el campesinado tuvo que asentarse dentro de la polis, esta comenzó a sufrir giros políticos y militares que afectarían inmediatamente el campo social y económico. Estos efectos anuncian "la decadencia de la ciudad como marco esencial de la civilización griega” (1986, p. 127).

Por lo tanto, este artículo tiene como objetivo presentar, a partir de la comedia de Aristófanes, cómo la acción ético-política del labrador dentro de Atenas comienza a relucir debido a la crisis social que padece el polites. Aristófanes, en piezas como Los acarnienses, Los caballeros y paz, fundamenta una idealización ética del hombre rural durante los últimos treinta años del siglo $\mathrm{V}$ a. C. No obstante, al final del texto se evidencia por medio de comedias como Los asambleístas y Pluto, la degradación del ideal campesino a causa del descenso del proyecto democrático.

\section{Aristófanes y el ethos idealizado del personaje labrador}

Las consecuencias que deterioraron la ciudad fueron percibidas por Aristófanes, quien, con su poesía, su reflexión y sinceridad puso en escena para que el ciudadano-espectador, víctima directa de la decadencia, tomara discernimiento respecto a las decisiones de los estrategas y gobernantes con los actos bélicos. Si bien la desintegración de la ciudad y la crisis moral afectaron al polites y georgós, indudablemente quienes más padecieron los desastres de la guerra fueron estos últimos, y Aristófanes claramente representó los padecimientos y adversidades que confrontó el labrador; esos padecimientos que expone el cómico refiere a los nuevos movimientos económicos, militares, religiosos y sociales. Pero, la doctora Pérez Monroy (1997) agrega precisamente dos circunstancias que desfavorecieron al georgós dentro de la vida cotidiana de la ciudad ateniense: el primer elemento que anuncia Pérez Monroy es el económico y cómo este menoscaba la vida social del campesino. Quizá el primer anuncio de advertencia que se halla en las obras del cómico que ilustra la complejidad del campesino para ingresar al mercado 5 se encuentra en Los acarnienses, cuando el héroe campesino Diceópolis

4 El historiador Tucídides narra este suceso con un sentimiento patriótico, expresando claramente la preocupación y desazón del campesino por abandonar sus tierras: "A causa, pues, de esta larga costumbre de vivir con autonomía fuera de Atenas, aun después de establecida la unidad, la mayoría de los atenienses de los tiempos antiguos y de los posteriores hasta hoy han nacido y vivido en el campo por esta tradición; por ello llevaron a término la evacuación en unión de toda su familia con dificultad, dado sobre todo que hacia poco que, después de las Guerras Médicas, habían recobrado sus posesiones; y se entristecían y soportaban mal el abandonar sus casas y sus templos, que habían sido los suyos tradicionales desde la época de la antigua constitución, así como el estar a punto de cambiar su género de vida y de hacer algo que significaba tanto como abandonar cada uno su ciudad" (Th. II, 16).

5 El profesor Julián Gallego argumenta la razón por la cual Aristófanes crea estos versos haciendo una crítica a la nueva forma de sostenerse económicamente el campesino en la ciudad, dado que en Atenas había un característica 
narrando los primeros versos de la obra, expresa un anhelo por regresar a la kóme y poder autosostenerse económicamente:

Con la mirada puesta en mi tierra, deseoso de paz, aborreciendo la ciudad, añorando mi pueblo, que jamás pregonó "compra carbones", ni "compra vinagre", ni "compra aceite", y ni siquiera conocía eso de "compra", pues por sí mismo producía de todo y no había allí quien te aserrara el oído gritando "compra". (Ar. Ach. 30-36)

Al tener que ingresar al nuevo sistema económico, el campesino tuvo que buscar un trabajo asalariado en la polis, para poder comprar los alimentos. Algunos decidieron ir a la guerra para recibir un salario especial que el Gobierno ateniense les brindaba, otros menos afortunados ingresaron al trabajo de esclavo y jornalero (Pérez Monroy, 1997, p. 17), por lo cual se formó una masa de desempleados y desposeídos en Atenas. Aristófanes, en Los acarnienses presenta en los últimos versos de la pieza a un labrador completamente desahuciado, esta exposición del labrador desempleado describe la situación precaria en que vivían algunos campesinos:

(Entra un labrador sucio y harapiento)

Labrador: ¡Ay! desgraciado de mí.

Diceópolis: ¡Heracles! ¿Quién es éste?

Labrador: Un hombre desdichado.

$[\ldots]$

Labrador: Queridísimo amigo, ya que solo tú tienes treguas, dame una medida de paz, siquiera de cinco años.

Diceópolis: ¿Qué te ocurrió?

Labrador: Estoy hecho cisco: perdí mi yunta de bueyes.

$[\ldots]$

Diceópolis: Entonces, ¿qué necesitas ahora?

de "comercio precapitalista", propiedad económica que no conocían los aldeanos por su autosuficiencia en el campo económico. La idea de compra que origina el descontento del labrador aristofánico tal vez entrañe una primacía del valor de cambio sobre el valor de uso, ligada a una de las características del comercio en las sociedades precapitalistas que implica una subordinación de los productores directos a los precios del mercado. En este contexto, las expresiones que Aristófanes pone en boca de Diceópolis son importantes en cuanto al significado del ágora, la plaza comercial de la ciudad, para los sectores rurales independientes, mostrando cómo sus valores se ubicarían no del lado del mercado, sino del de la autosuficiencia" (2008, p. 81). 
Labrador: Tengo los ojos perdidos de llorar por los dos bueyes. Si tienes alguna consideración a Dércetes el Filasio, úngeme pronto con paz en uno y otro.

Diceópolis: ¡Desgraciado!, no ejerzo de médico público.

Labrador: Anda, te lo ruego, a ver si recupero de algún modo mis bueyes. (Ar. Ach. 1016-1035)

El segundo factor que afectó la vida social del georgós en la ciudad fue el militar, ya que los nombres de los campesinos aparecían seguidamente en las listas públicas. Si bien el dirigirse a la guerra le brindaba al campesino un salario especial, este no poseía conocimiento alguno de las formaciones estratégicas en el campo de batalla. Estas decisiones del Gobierno ateniense de enviar al labrador a la guerra solo era "una solución parcial a los problemas de aglomeramiento y a las pocas oportunidades de trabajo" (1997, p. 19). El coro de La paz, otra obra aristofánica, narra esta situación y reprocha la poca atención que tienen los gobernantes hacia los hombres rurales:

Y cuando no están en la guerra nos hacen picias insufribles, inscribiendo correctamente a unos y moviendo arriba y abajo en las listas a otros, hasta dos y tres veces: "Mañana se sale de campaña", y puede que alguno no haya comprado las provisiones, pues no estaba enterado de la marcha, y luego, plantado delante de la estatua de Pandión, se ve en la lista, y confundido por la desgracia sale corriendo con los ojos húmedos. Eso nos hacen a nosotros los campesinos; a los de la ciudad, menos, esos abandona-escudos a ojos de los dioses y los hombres. (Ar. Pax. 1178-188)

A pesar de que el campesinado sufrió varias afecciones a causa de los giros políticos, económicos y militares ocasionados por la guerra y los gobernantes posteriores a Pericles, aquellos siempre trataron de mantener una posición correcta ante los desmedidos actos bélicos. El ethos del georgós siempre tuvo una "fuerza moral", dado que desde la poesía hesiódica se expresa cómo el aldeano llevó su vida laboral, social y religiosa adecuadamente logrando ser un grupo socialmente bien organizado. El factor "psicológico" que contenía el campesino en la poesía de Hesíodo se perpetuó durante dos siglos (VI-V a. C.) para alcanzar, dentro de la Atenas democrática, una idealización, ya que "el agrarismo se preservó también en la cultura de la polis por una fuerza moral" (Davis Hanson, 2003, p. 263). A través de las historias homéricas, específicamente la de Orestes, Eurípides reflejó una idealización al sector agrario debido a la decadencia moral y política del ciudadano, pues describe a partir de la personificación de un labrador de clase baja la vida tranquila del campesinado y, en consecuencia, esas acciones lo llevaban a ser un hombre social y políticamente correcto. También a través de un viejo Mensajero hizo que el espectador fijara con más atención la conducta del campesino, puesto que el trágico puso a este como el hombre 
que debe gobernar la polis. Se incluye en la idealización euripidea el elemento político, ya que en Orestes y Electra hay un interés por parte del poeta en promover un juzgamiento al debilitamiento socio-político de los politai.

La obra de Aristófanes, teatro de escenifica con claridad la idealización del campesino, muestra los dos rostros que tuvieron los georgoi frente a la crisis. En las primeras comedias como Los acarnienses y Los caballeros aparecen unos personajes campesinos violentos e individualistas, su comportamiento alterado se debe a la hybris cometida por los gobernantes y estrategos. El personaje campesino solo piensa en regresar a sus aldeas y volver a estructurar su vida rural, ya no desea continuar sometida a las decisiones de una Asamblea "boquiabierta": "[S]e aprecia que las actitudes de los campesinos se definían en función de los beneficios o perjuicios que recibían en las situaciones particulares" (1997, p. 20).

Un segundo rostro que se halla en la obra del cómico es la idealización del campesino y su posición ético-política ante las catástrofes de la guerra. La pieza que representa esta conversión del campesinado es La paz, dado que el labrador durante las guerras peloponesias siempre fue un impulsor de detener las acciones bélicas entre Atenas y Esparta. Cuando estas dos ciudades firmaron la paz en el 421 a. C., Aristófanes celebró esta decisión creando aquella pieza teatral. Julieta Pérez Monroy lo justifica del siguiente modo: En ella ( $\mathrm{La}$ Paz) presenta al pequeño campesino como el principal sector interesado en la pacificación de Grecia (1997, p. 21).

\section{La problemática social y económica del georgós. Lectura desde Los acarnienses y Los caballeros}

En la comedia aristofánica se percibe el primer momento que se mencionó anteriormente acerca de la posición crítica del campesinado durante los primeros diez años de guerra (431 a. C.-421 a. C). En Los acarnienses y Los caballeros, Aristófanes recrea una cantidad de situaciones que deducían la incomodidad, el malestar y la desazón del georgós por el trato dado dentro de la ciudad. Es indispensable esclarecer este primer momento desagradable del campesino dado que es a partir de la crisis del sector rural y la decadencia moral de los politai que aquel sector tomara en la comedia antigua la idealización que tanto expone Davis Hanson (2003). En la época que fue representada Los acarnienses (425 a. C.), el sector rural ya sentía la necesidad de volver a tierras áticas, por esto aparece una indicación en favor de la paz. El héroe campesino Diceópolis expresa en su primera aparición la incomodidad que siente el labrador de habitar en la ciudad, además está harto de la negligencia de la Asamblea, que solamente se dispone a hablar acerca de la guerra:

Diceópolis: Los prítanes no llegan sino a deshora, y luego - imagínatelo- ¡cómo se empujan y precipitan los unos sobre los otros para 
disputarse el primer banco, abalanzándose todos a la vez! El que haya paz no les importa nada ¡Oh! ciudad ¡Oh! ciudad. (Ar. Ach. vv 24-27)

Acarnienses es la primera prueba fehaciente del desespero contenido por el labrador; soportar una peste y ver cómo a diario disminuían los bienes y el alimento llevó a Aristófanes a crear a un héroe campesino y un coro conformado por unos ancianos campesinos bruscos, individualistas y violentos. Las conductas de estos personajes son el reflejo del georgós, una desesperanza que van experimentando al presenciar el caos en la ciudad y la destrucción total del campo.

Este acercamiento a la postura del personaje campesino dentro de las primeras obras será breve, dado que lo principal en este escrito es abordar la idealización del campesino y dentro de esta la posición ético-política que toma correspondiente al momento dificultoso que pasaba la polis. Los acarnienses y Los caballeros es la introducción a esa actitud ética y política, teniendo claro que dentro de estas dos piezas aparecen posiciones que tal vez tuvo el labrador respecto a los conflictos y vida en la ciudad. Diceópolis y el coro de Acarnas en Los acarnienses son la minoría que busca la paz dentro de Atenas, una minoría en contra de la cantidad de personajes que el poeta recrea como partidarios de la guerra (Heraldo, Embajador, Pseudodartabas, Lámaco, etc.). Hay que precisar que Aristófanes nace en el demo de Acarnas, por tanto hay una identificación y similitud entre el poeta y su creación artística, Diceópolis (Ar. Ach. vv. 440-444). Esta similitud se amplía cuando el cómico integra al héroe un ideal tradicionalista y con una posición en contra de la guerra (Plácido, 2012). Esta condición que le da Aristófanes al héroe de estar a favor del cese de enfrentamientos tiene la finalidad de exponerle al ciudadano-espectador que el georgós está exhausto del aprisionamiento socioeconómico que tiene dentro de Atenas. Por esta razón es que Diceópolis, con una conducta egoísta e individual, realiza la tregua de guerra para él y su familia (197-202), y gracias a la tregua, el héroe campesino regresa al campo con su familia y realiza una fiesta en honor a Dionisio:

Diceópolis Fales, camarada de Baco, compañero de jarana, noctívago, adúltero, bujarrón, después de cinco años, te saludo, contento de mi regreso al pueblo, tras haberme hecho treguas para mí solo y librado de guerras, 'pejiguerras' (Ar. Ach. vv. 263-270).

En los versos 19-22, Aristófanes recrea con genialidad el interés del campesinado por asistir a la Asamblea y dialogar acerca de la paz. Sin embargo el poeta representa, como fuente histórica, la indiferencia de los asambleístas para deliberar sobre la guerra y su terminación: "El que haya paz no le interesa nada" (Ar. Ach. v. 27). Esta ilustración, parafraseando a Domingo Plácido (2012), es la actitud de Aristófanes que refleja dos momentos: primero, la crítica a la polis de no interesarse por la paz; segundo, la inclinación de los demoi rurales por el restablecimiento de la paz. La actitud de Aristófanes en aquella época y la creación de Diceópolis expresan la visión relevante que tiene para el cómico lo rural. Si bien no existía esa teoría histórica que el sector agrario es la base en la que se consolidó la polis, el cómico reconoce en Los acarnienses que existían 
problemas económicos por el arrasamiento de los cultivos en el Ática, por esto el héroe creará un mercado para las aldeas, los megarenses, laconios y beocios, pero cerrará el mercado a Lámaco, representación directa de aquellos que aún vociferaban la idea de continuar la guerra (Ar. Ach. vv. 719-722).

El coro de acarneos es la representación vivificante del campesinado de la época de Maratón y Salamina ${ }^{6} \mathrm{y}$, por consiguiente, la figura del tradicionalismo en Aristófanes. La actitud del coro es más violenta y tormentosa que la de Diceópolis, ya que aquel anhela, al igual que el héroe, el regresar a la vida rural, pero Diceópolis realiza la tregua solo para él, esto ocasiona una frustración en los ancianos campesinos, tanto que deciden atacarle hasta matarlo (280-325). Pero, luego de la explicación y sabiendo que el héroe se enfrentará con el verdadero causante de la guerra (Lámaco), hay un parte del coro (hemicoro II), que respalda al héroe nombrándolo como hombre "justo" (Ar. Ach. vv. 560 y 661). Aristófanes con esta sentencia del hemicoro II da pinceladas de idealización de los georgoi que posteriormente se verá más abundante en La paz.

La comedia Los caballeros corresponde a la máxima crítica que desarrolló Aristófanes contra el demagogo Cleón y su sistema político. Por tal motivo, en esta pieza no reluce mucho el personaje campesino, ya que la "idea crítica" de la obra va dirigida a la demagogia y a los habitantes de la ciudad que se encuentran ensimismados por las adulaciones y discursos retóricos. Pero la figura del héroe, Morcillero, realiza alguna alusión referente al sufrimiento de los campesinos dentro de la polis a causa de las decisiones del "vendedor de cueros"8. En Los caballeros tanto en el proepirrema como en el epirrema el Morcillero está disputando con el Paflagonio y le hace precisiones acerca de los malos funcionamientos y engaños que ha hecho en toda Atenas; entre los versos 315-332, el poeta cómico pone en boca del héroe un engaño de mercado que hizo Cleón a los campesinos, ya que el georgós no conocía el sistema de compra de los atenienses urbanos:

Morcillero: Si tú no entiendes de suelas, tampoco yo de morcillas; tú, que cortabas sesgado cuero de buey raído para que pareciera macizo y se lo vendías engañosamente a los campesinos; y antes de llevarlo un día, había dado de sí más de dos palmos. (Ar. Eq. vv. 315-319)

6 El personaje Anfíteo narra las características de este coro de ancianos campesinos, hombres con ideales completamente tradicionales, que añoran la unión y gallardía de la Atenas antigua, la de las Guerras Médicas: "Venia corriendo aquí con las treguas, pero las olieron unos ancianos de Acamas, unos vejetes leo recios, tercos como alcornoques, inflexibles, excombatientes de Maratón, duros como leños de arce" (179-182).

7 Esta noción de idea crítica la trae a colación Luis Gil para señalar la posición pedagógica y ética de la comedia aristofánica: 'La 'idea crítica' es la noción que este se ha formado sobre una situación de gravedad que afecta por igual a todo el cuerpo ciudadano. Se manifiesta en el comienzo de la pieza, evidenciándose en su final el sentido en que quisiera ponerle un remedio. Esta idea crítica, sin la cual el tema cómico sería imposible, es la de Aristófanes como ciudadano y no es excesivamente original" (1996, p. 19).

8 En Los caballeros, Cleón es representado como el Paflagonio, que traduce 'vendedor de cueros'. Al inicio de la obra, uno de los siervos del Paflagonio narra el futuro inmediato de Atenas dicho por un oráculo: "Después de eso, viene su ruina. Efectivamente, le sucede un vendedor de cueros, el Paflagonio, rapiñador, vocinglero con una voz estruendosa como el Ciclóboro" (Ar. Eq. vv. 134-138). 
Además el coro de caballeros, una clase aristócrata, también expresa el repudio hacia el Paflagonio por el acto engañoso hacia el campesino, aquí Aristófanes expone que todas las clases sociales de la ciudad lamentaban el abandono del Gobierno ateniense hacia el campesinado. Si la estrategia militar periclea afectó considerablemente al sector rural, no hay duda que los ideales belicistas de Cleón y su indiferencia a los habitantes que deseaban la paz afectó íntegramente la vida de los georgoi. Los versos 328-329 muestran la impotencia del campesino por no hallar una vida digna dentro de la ciudad y el padecimiento porque la Asamblea no toma una decisión para el cese de hostigamientos: "Y entretanto, al hijo de Hipodamo ${ }^{9}$ se le caen las lágrimas contemplándote" (vv. 328-329).

En el epirrema de la obra, Aristófanes contempla la vida del campesino y cómo el restablecimiento de su vida social, laboral y religiosa lo llevaría a asimilar y aprehender la fuerza y vitalidad moral. En los versos 801-809, el poeta presenta la primera referencia de idealización. Esta primera noción de sublimidad se da a partir de un argumento utópico: el poeta idealiza al campesinado si en algún momento ulterior el georgós regresa a su vida rural y recobra aquellos ánimos y la "fuerza moral" y ética que durante más de dos siglos ha conservado:

Morcilero: ¡Por Zeus!, de que ocupe el poder en Arcadia no te cuidas, sino más bien de robar y recibir sobornos de las ciudades. Entretanto, el pueblo, obnubilado por la guerra, no ve tus sucios manejos $\mathrm{y}$, forzado por el provecho que saca del salario, te mira boquiabierto. Pero, si un día regresa al campo para vivir en paz, si recobra sus ánimos comiendo cebada tostada y entra en tratos con el borujo, reconocerá qué clase de bienes le arrebataste fraudulentamente con la percepción de este salario. Entonces vendrá contra ti con la acritud del campesino, en busca del voto de tu condena. Eso lo sabes tú y por ello le engañas y le haces soñar contigo. (Ar. Eq., vv. 801-809)

Jimena Schere afirma que en estos versos se "construye la imagen del pueblo como el conjunto de campesinos emigrados durante la guerra que, desprovistos de sus campos y de su fuente de subsistencia, viven hacinados en la ciudad y dependen del salario público" (2011, p. 337). Sin embargo, no se puede detener en esta concepción de dolencia del campesinado, debe analizarse también la manera como Aristófanes maneja el discurso con el fin de fortalecer más la figura del georgós y del personaje campesino. Los versos anteriormente citados expresan, además, una posición cimentada en ideales tradicionales de la kóme, Davis Hanson (2003) lo resume como una posición "que simboliza y encarna la dignidad de la polis agraria" (p. 266). La añoranza que presenta Aristófanes por la antigua Atenas ${ }^{10}$ es una posición singular del poeta que expresa en la mayoría de sus obras, pero en Los caballeros puede tener otra connotación; el

10 En los versos 1323 y 1327 de la pieza Los caballeros, Aristófanes exhibe su anhelo por la Atenas de inicios del siglo V Su añoranza y amor por ese momento de la ciudad se debe a esos valores morales que le proporcionaban al ciudadano un comportamiento solemne y moderado. 
anhelo hacia aquella Atenas referencia también la vida que tuvo la aldea, dado que antes y después de las Guerras Médicas, los demoi del Ática llevaron una vida considerablemente tranquila fortaleciendo aun su ethos viéndose reflejado este comportamiento correcto en los momentos de crisis, por ejemplo, en el año en que se representó Los caballeros.

Los acarnienses y Los caballeros son el reflejo de la caducidad de una época "ilustrada" y de un proyecto democrático inacabado, estas comedias son la representación de una decadencia de valores políticos y sociales. Pero, estas dos piezas son la imagen de unos campesinos desprendidos de sus tierras y acciones, sometiéndose a nuevos sistemas económicos y laborales. Sin embargo, el ethos del georgós no decae ni llega a tomar acciones desmesuradas (hybris), su comportamiento siempre es moderado, paciente y deseoso de paz, por esto Aristófanes hace hincapié en este sector social, ya que adquiere el mismo ideal de pacifismo y añora el fin de hostilidades para regresar de nuevo a sus tierras y reorganizar su vida dentro de la aldea (Gil Fernández, 1996, p. 86). Además hay que analizar los detalles de idealización en estas dos comedias, aunque no son abundantes las alusiones por el momento en que se representaron (424 - 425 a. C.), Aristófanes sabía con exactitud que los georgoi conservaban los valores religiosos, morales y sociales, contrario a los politai que se arroparon con el discurso retórico y belicista de los demagogos presentando así una crisis.

\section{La Paz y la idealización del campesinado}

Tras la muerte de Pericles (429 a. C.) y de Cleón (422 a. C.), la Hélade tuvo la posibilidad de poner fin a la guerra que llevaba alrededor de diez años, puesto que en Atenas y Esparta habían partidarios de finalizar los hostigamientos, uno de estos era Nicias, quien el principal contrincante de Cleón. Por lo tanto en el 421 a. C. la paz de Nicias se firmó y Grecia comenzó a reconstruir y restablecer la vida que llevaban antes de la guerra. En ese mismo año, y con la satisfacción del cese de enfrentamientos, Aristófanes crea y representa la comedia La paz que, como lo describe Pérez Monroy (1997), es "la celebración de un acontecimiento significativo (p. 21). Si bien esta creación teatral es el entusiasmo de haber acordado la paz, el objetivo principal del poeta cómico es presentar a los labradores como la comunidad que estuvo interesada, permanentemente, por la pacificación de todo el territorio helénico.

En las obras inmediatamente anteriores a La paz, Aristófanes recreaba dos momentos del campesinado: lo primero, eran los padecimientos que soportaban dentro de la ciudad; lo segundo, fue el ensalzamiento que hizo el poeta a este sector, ya que a pesar de los sufrimientos en la polis, el georgós mantenía una posición ético-política adecuada y acorde a los ideales de la antigua Atenas. En La paz, no se presentan esos dos momentos, solo se exhibe la idealización del hombre rural. La paz es la valoración política y ética que le da el poeta al labrador, puesto que en primera instancia los personajes campesinos exteriorizan 
sus ideales de pacifismo y anhelan recuperar a Eirene (Paz) para volver a las aldeas; Aristófanes manifiesta a través del héroe y el coro de labradores, la felicidad de regresar a las tierras áticas y recobrar la vida rural que tanta categoría moral le ha dado.

La vida rural y el agrarismo son posiciones sociales y de profesión respectivamente, pero también adquieren un incentivo para la supervivencia de la polis. En Los trabajos y Días de Hesíodo, y en Electra y en Orestes de Eurípides, se presencia una configuración de la vida socio-religiosa y la labranza en los habitantes de la aldea como una manera de demostrar la excelencia moral que allí se aposenta. Aristófanes se perfila directamente en mostrar, a través de $\mathrm{La}$ paz, la honestidad, moderación, valentía, camaradería y prominencia ética, social y cultural del georgós. Por esto La paz para Gilbert Norwood (Citado por Pérez Monroy, 1997) y Davis Hanson se trata de la "idealización de la vida rural". La fundamentación aristofánica en la obra era clara: idealizar al labrador, esto debido a que empezó a notar una indolencia en el ciudadano y un deterioro moral del mismo, saliendo a relucir, entonces, los valores de labranza y moralidad en el propio campesino, declarando tácitamente a este como un individuo íntegro en conductas laborales y éticos-políticas para Atenas: "La labranza al aire libre contribuía a un físico saludable. Controlaba la pereza, resultando en una población que deseaba la paz, pero era formidable en la guerra, en contraste con la plebe urbana cobardemente holgazana" (Davis Hanson, 2003, p. 264).

En La paz se encuentra, al igual que en Los acarnienses, un héroe campesino y un coro de labradores ancianos, pero las dos representaciones de campesinado en ambas obras difieren. El héroe de La paz, Trigeo, acompañado del coro, tiene una posición idealizada y una actitud que va acorde a su vida rural. Trigeo, cuya profesión es viñador (Ar. Pax.188-189), tiene el objetivo de subir al Olimpo y dialogar con los dioses para dar fin a la guerra, pero al llegar se encuentra a Hermes solo, ya que los olímpicos decidieron irse a un lugar más alejado y no intervenir con los helenos porque prefirieron continuar con la guerra (vv. 200-218), por lo que el dios Pólemos es quien impera en Grecia poniendo a Paz dentro de una cueva (220-224). A partir de aquí Trigeo se da a la tarea de recuperar a Paz y que Pólemos no destruya todas las ciudades griegas. En los versos 289-300, Aristófanes hace la primera alusión de idealización del campesinado, puesto que el héroe hace un llamado valiente a todos los helenos para liberar a Paz y que tanto el héroe como el coro puedan regresar a sus tierras áticas:

Trigeo: Ahora es cuando viene a cuento aquella canción de Datis, la que cantó una vez en pleno día mientras se la meneaba: “¿Qué placer, qué alegría y qué jolgorio!". Ahora es el momento, hombres de la Hélade, de que nosotros, una vez libres de problemas y guerras, saquemos de su encierro a Paz, a la que todos amamos, antes de que lo impida algún otro mazo. ¡Ea, labradores, comerciantes, carpinteros, obreros, metecos, extranjeros e isleños, venid aquí pueblos todos, venid a toda prisa con palas, palancas y sogas! Ahora nos es posible hacernos con la buena diosa. (Ar. Pax. 289-300) 
El llamamiento que hace el héroe campesino a todos los griegos puede analizarse en el sentido de superioridad ética, de temperamento y cumplimiento del deber, es decir, Trigeo reconoce la mala conducta por parte de los atenienses y toma una postura de salvador y líder (Navarro González, 1978). Esta imagen gallarda y prudente de Trigeo es la irradiación de la posición ético-política que mantuvieron los georgoi durante los diez años de la guerra. Cabe agregar que este grito del héroe puede ser algo metafórico; es un grito jubiloso y de alegría, porque existe la posibilidad de regresar al campo y labrar la tierra con honestidad, sencillez y lealtad, convirtiéndose el cuerpo del labrado en un cuerpo fuerte y bello, física y moralmente.

Aristófanes impregna al coro una felicidad interminable, él está seguro de que Paz saldrá de la cueva y reinará otra vez la Hélade. Pero Trigeo, con su sophrosyne calma al coro, dado que aún no se ha liberado a Eirene; sin embargo, afirma que cuando se libere y estén en la aldea, "ya podremos navegar, quedarnos en casa, movernos, dormir, darnos un banquete, ir de romería, jugar al cótabo, pasarlo como los sibaritas y gritar iyuju, yuju!" (340-342). El coro responde con una oda, un canto de nostalgia y debilidad por haber aguantado una década de hostigamientos, malos tratos, engaños y la reconfiguración de la vida dentro de Atenas. Esta oda se canta en pasado, es una superación que tuvo el labrador referente a la guerra y la reorganización social y cultural que tendrá en la kóme gracias a la paz de Nicias:

Coro: Verías que soy amable y que he rejuvenecido, libre de mis problemas. Y es que ya bastante tiempo perecimos y nos fastidiamos en nuestro vagar errante, al Liceo y del Liceo, con la lanza y el escudo. Ea, lo que más gozo hacer nos diera, venga, dilo, pues a ti jefe supremo nuestro te ha elegido la buena fortuna. (Ar. Pax. vv. 350-360)

Entre los versos 400-507 están Trigeo, el coro y Hermes intentando salvar a Paz. En el verso 511 aparece una sentencia de Aristófanes en boca del héroe, que se relaciona claramente con la tesis de Davis Hanson. Hanson (2003) afirma que la acción agraria - agrarismo - brinda al campesinado una fuerza social y ética que le ha ofrecido a este sector una amalgama de valores, posibilitándole, además, una mejor calidad de vida: "Los labradores son los únicos que hacen avanzar el trabajo, nadie más" (Ar. Pax. v. 511). El verso 511 de la Paz también es citado por Hanson sentenciando que "los granjeros en el drama ateniense de los siglos V y IV simbolizan y encarnan la dignidad inherente de la polis agraria entera" (p. 266). La acción elaborada por el coro permite que Trigeo enaltezca su labor, esto se analiza desde dos aspectos notables: primero, la vida rural siempre tuvo un sentido de pertenencia que le brindaba al campesino trabajar honesta y valientemente, cuando sus tierras fueron arrasadas por los laconios, aquellos tomaron la postura pacifista por el deseo de regresar al campo y seguir con su vida social y religiosa. Además, se percibe en el personaje campesino aristofánico un panhelenismo; la unión de todas las ciudades griegas para crear una única unidad política. El segundo motivo por el que Aristófanes sentencia la idealización del georgós es por la acción del trabajo, quizá no tuvo 
una notoriedad como lo fue la política o lo militar, sin embargo la acción de labranza le propiciaba, como se describe también en Eurípides, ser un hombre "justo", puesto que, como lo expone Davis Hanson (2003), "era un trabajo inherentemente noble concentrado en alcanzar las necesidad esenciales, no en obtener ganancias superfluas" (p. 265). El verso 511 es la expresión directa del dinamismo social, político y ético del campesino.

Esta sentencia cumbre del poeta cómico es también la máxima que posibilita que Paz, Opora y Teoría salgan de la cueva. Los versos 516-518 son el último aliento que sacan el coro, Trigeo y Hermes para la liberación de Eirene y retornar al campo. Liberada Paz, Trigeo brinda un saludo donde expresa que nuevamente podrá regresar al campo y cosechar sus productos: “ $\mathrm{O}$ h señora que nos regalas la vid!" (519). La liberación de Paz le produce a Trigeo, al coro y a aquellos que deseaban el cese de la guerra una felicidad inabarcable (vv. 539-540), tanto que el héroe describe como los fabricantes de armas, quienes caracterizan a los que aún querían la guerra, se lamentan porque la diosa reinará nuevamente la Hélade. La liberación de Paz hace que Trigeo narre con furor y apuro el regreso al campo, pues la labranza y la vida se llevarán armónicamente:

Trigeo: Oídme, gente: que se retiren los labradores al campo cuanto antes, llevando consigo sus aperos de labranza, y sin lanzas, espadas ni jabalinas, que ya todo aquí está bien lleno de nuestra antigua paz. Vamos, todo el inundo a su trabajo en el campo, cantando el peán. (Ar. Pax. 551-554)

Aristófanes ha empleado en 600 versos, a lo sumo, la invención poética y la "idea crítica", para representarle al ciudadano-espectador el verdadero ethos del campesinado, la actitud de este que configura con evidencia una superioridad moral, se exterioriza como un hombre "justo", valiente, humilde, honesto, leal y prudente, y para el poeta el valor o ideal de mayor relevancia es la postura radical frente a la guerra, ya que fue sector que más rechazó los enfrentamientos. En La paz, el referente de fuerza moral como areté y ethos del campesino es el deseo de liberar a Eirene y que ella retome su tarea de reinar por toda Grecia. La invención poética del cómico de personificar a Paz como diosa, y de que el campesino sea quien la libere, representa esencialmente la reconfiguración que tendría Grecia, Atenas, la kóme y sus habitantes gracias a la paz de Nicias. El coro, en una oda de 19 versos, exhibe esa felicidad y tranquilidad que produce saber que la paz rige en todo el territorio helénico:

Coro: ¡Hola, hola, queridísima, qué contentos estamos de tu venida! Abatido me tenía la nostalgia de ti. Un dios me hacía desear meterme en el campo. ¡Tú eras nuestra mayor ganancia, oh diosa añorada, la de todos cuantos la vida del labrador llevamos! Porque solo tú nos ayudas. Muchas cosas nos pasaban antes por tu causa, cosas dulces, amables y gratuitas. Tú eras para los campesinos la cebada tostada y la salvación. Conque las vides, los higos nuevos y todas las plantas te acogerán contentos con una sonrisa (Ar. Pax. vv. 581-600). 
Los últimos seiscientos versos de La paz hacen referencia al regreso del campesino a su tierra y la realización de una fiesta en honor a Paz y Cosecha, con la finalidad de que estas dos divinidades siempre protejan la vida y labranza en la aldea. La Paz fue, sin duda, la manera teatral de enarbolar el ethos del campesinado a través de la vida social de estos y del agrarismo. El verso 511 de esta pieza expresa el agrarismo como algo más que una acción económica, es una virtud que proporciona una conducta moral adecuada, es decir, cómo la labranza concede al labrador una supremacía ética que soporta la cultura agraria y civil de la polis.

\section{Asambleístas, Pluto y la definitiva crisis del ciudadano-campesino}

Para culminar este análisis literario e histórico que se desarrolló con la comedia aristofánica para entender la posición ética y política del campesinado y su posterior idealización, es pertinente abordar la representación del labrador en el Pluto (388), una comedia que ya no emprende la mofa a alguna celebridad pública o intelectual, ya la "idea crítica" que se exponía anteriormente no aparece con tanta claridad. La última pieza conservada de Aristófanes no se puede situar en la comedia antigua, sino que se posiciona como una de las primeras obras de la comedia media, dado que Aristófanes se centra en las costumbres y la vida social del ateniense del siglo IV a. C. Pluto es una comedia social que describe la grave situación de Atenas, que está golpeada por la pobreza y la pérdida de autonomía, pero no se guiará por la sátira política, se hará una recreación de la crisis del individuo y a partir de allí se plantea la problemática social. Esto posibilita, entonces, hilar la figura del campesino en el último Aristófanes con el georgós de Menandro.

La paz de Nicias que tanto había beneficiado al campesino y al polites se rompió en menos de tres años, debido a que algunos aliados de Esparta no estuvieron de acuerdo con el cese de enfrentamientos, ocasionando, entonces, la guerra de Mantinea (418 a. C.), después de terminada esta guerra la polis ateniense comenzó a sufrir un descenso en las victorias contra Esparta, por lo que aparecería, de nuevo, la crisis moral, económica y social, el proyecto democrático que se impulsó durante el 410 a. C.-411 a. C. se derroca por la fuerza oligárquica ateniense guiada por Alcibíades (Th. VIII, 42-52). La continuación de la guerra y la poca estabilidad constitucional causó que en el 404 a. C. Atenas se rindiera ante el poderío espartano y persa, además que el hambre y la pobreza doblegó la grandeza de la polis, los Muros Largos fueron destruidos y tropas peloponesias se posaron en el territorio ateniense. "Así se desploma el poderío de Atenas, al final de una guerra que había durado más de un cuarto de siglo y de la que la ciudad salía arruinada y descompuesta" (1987, p. 68).

Este desastre bélico y político provocó una miseria campesina, puesto que después de la guerra solo 5000 atenienses poseían tierras y el reparto de tierras 
hecho por los demócratas procedía cada vez menos de la vida rural, esto, según Claude Mossé, provocó que Atenas estuviera al margen de una crisis agraria (Mossé, 1987, p. 78). Aristófanes en Los Asambleístas y en Pluto indica con precisión esta problemática agraria. En los versos 590-599 de Los Asambleístas, Praxágora plantea el argumento del bien común, y sostiene que los recursos se están dirigiendo solo para un bando y que el campesino y el esclavo están sufriendo las necesidades:

Praxágora: Os diré que es preciso que sean comunes los bienes de todos, que todos tengan parte del común y vivan de los mismos recursos, y no que uno sea rico pero el otro pobre. Que no posean unos grandes extensiones y otros no tengan ni para su fosa; que no tengan unos montones de esclavos y que otros carezcan de un mal ayudante. (Ar. Ec. 590-595)

Acto seguido afirma que la repartición de tierras será equitativa (597-599), esto brinda una luz acerca de la posible crisis agraria que presentó en Atenas. En Pluto, la representación del personaje campesino tiene similitud con el de Acarnienses, unos labradores desahuciados y empobrecidos por las guerras, pero en aquella pieza no hay una crítica a los gobernantes que promocionaron la guerra, aparece mejor una narración de la vida cotidiana del campesino, Crémilo, el héroe, que le reprocha a Penía (Pobreza) por la situación que están enfrentando los labradores por la inequidad que se posó en la ciudad:

Crémilo: ¿Acaso podrías tú procurar algún bien aparte de quemaduras del baño, arrapiezos famélicos y una turbamulta de viejezuelas? Nada te digo, dado su número, de todos los bichos, mosquitos y pulgas que nos fastidian con su barullo en torno a nuestra cabeza y nos despiertan y nos dicen: «Tendrás hambre, conque, arriba». Y aparte de eso, en vez de manto se tienen harapos; en vez de cama, un jergón de juncos repleto de chinches que mantiene en vela a los que están acostados sobre él; en vez de alfombra, una estera deshilachada y en vez de almohada, una piedra enorme bajo la cabeza. Y a la hora de comer, en vez de pan, hojas de berza; en vez de galletas, rábanos; en vez de taburete, un orinal desportillado y en vez de artesa, el costado de un tonel igualmente desportillado. (Ar. Pl. 535-546).

El mensaje de Pluto es, como lo expresa Luis Gil (1996, p. 89),

[M]ás claro todavía. La riqueza acumulada, gracias a la descomposición política, era un mal que socavaba los cimientos de la sociedad y de la patria. Aristófanes sueña con una nueva situación, en la que la honradez y la laboriosidad fueran las únicas fuentes de la prosperidad y del bienestar. 
Esto supone, entonces, una inmensa desmoralización de Atenas, debido a la pérdida de autonomía y poderío, personajes como Agirrio o Pánfilo gobernarían sin prestigio y sin ningún conocimiento de la ciudad, esto fue desfavoreciendo al campesino, porque si en los años 430 a. C. -422 a. C. no hubo interés por el sector rural, en los primeros años del siglo IV con la crisis agraria y la poca transparencia para repartir tierras llevaría a los georgoi a desintegrarse de su vida rural y su labranza, teniendo que involucrarse en otro trabajo para sobrevivir. Esto expresa, entonces, el decaimiento de la fuerza moral del ciudadano-campesino, causando así una decadencia cultural y social en toda Atenas, ya que el agrarismo fue aquella acción que sostuvo la polis ateniense económica y culturalmente.

\section{Consideraciones finales}

Se presentó en el desarrollo del texto la condición hostil que enfrentó el labrador en los últimos treinta años del siglo $\mathrm{V}$ a. C. donde se presenciaron cantidad de situaciones complejas que sufrió Atenas y no fueron manejadas adecuadamente. La guerra del Peloponeso fue el factor clave que produjo las problemáticas produciendo de este modo un declive político, social y moral; el anhelo de guerra para una cantidad considerable de atenienses causó que el ethos del ciudadano tomara una postura excesiva e incorrecta, ya que el discurso guerrerista impartido por algunos retóricos provocó en el polites una necesidad de victoria para seguir conservando la grandeza de Atenas en toda la Hélade. Pero la hybris presentada por el ateniense no le pareció conveniente al cómico Aristófanes que prefirió enaltecer, idealizar y fijar su mirada al labrador (georgós) como individuo política y moralmente correcto y con un patriotismo adecuado. El campesino en la comedia aristofánica toma dos posturas que le proporcionan la calificación de hombre ideal: la primera, es el modo como el cómico le ofrece la categoría de héroe por medio de acciones cotidianas de labranza y comportamientos éticos y políticos consonantes a los valores griegos; y segundo, la idealización, el heroísmo y sus pautas correctas son, además, críticas directas al hombre urbano, al ateniense que vive dentro de la ciudad que ha tomado unas prácticas inadecuadas y discordantes a los valores tradicionales de la Hélade, causando así un desvío en sus hábitos morales y ejercicios políticos. Aristófanes, el mayor representante de la comedia antigua, recurrió a su invención poética para darle al campesino una figura correcta y un rostro y un ropaje heroico que significaran, así, la idealización y el protagonismo dentro de una ciudad avasallada por la guerra y carcomida por los demagogos y los ciudadanos con conductas excesivas. 


\section{Referencias}

Austin, M. y Vidal, P. (1986). La época de la crisis. En Economía y sociedad en la antigua Grecia (pp. 127-148). Barcelona: Paidós.

Calonge Ruiz, J. y Torres Esbarranch, J. J. (1990). Tucídides. Historia de la guerra del Peloponeso (libros 1-2). Madrid: Gredos.

Davis Hanson, V. (2003). La idealización de la clase labradora. En J. Gallego (ed.), El mundo rural en la Grecia antigua (pp. 263-268). Madrid: Akal.

Gallego, J. (2003). Comunidad aldeana y sociabilidad campesina en la Grecia antigua. En J. Gallego (ed.), El mundo rural en la Grecia antigua (pp. 327-380). Madrid: Akal.

Gallego, J. (2008). La economía campesina en el mundo antiguo. Perspectivas, intercambio y autarquía. En P. Miceli y J. Gallego (eds.), Habitar, producir, pensar el espacio rural. De la Antigüedad al mundo moderno (pp. 59-99). Madrid: Miño y Dávila.

Gil Fernández, L. (1996). Aristófanes. Madrid: Gredos.

Gil Fernández, L. (2011). Aristófanes. Los acarnienses. Madrid: Gredos.

Gil Fernández, L. (2011). Aristófanes. Los caballeros. Madrid: Gredos.

Macía Aparicio, L. (2007). Aristófanes. Comedias II. Madrid: Gredos.

Macía Aparicio, L. (2007). Aristófanes. Comedias III. Madrid: Gredos.

Mossé, C. (1987). Historia de una democracia: Atenas. Madrid: Akal.

Navarro González, J. L. (1978). La estructura interna del héroe cómico. Cuadernos de Filología Clásica, 15, 137-166. Recuperado de http://revistas.ucm.es/index. php/CFCA/article/view/CFCA7878220137A

Pérez Jiménez, A. y Martínez Díez, A. (1978). Hesíodo. Obras y fragmentos. Madrid: Gredos.

Pérez Monroy, J. (1996). Aristófanes: guerra y sociedad en el imperio ateniense. Nova Tellus, 14, 45-76. Recuperado de https://revistas-filologicas.unam.mx/ nouatellus/index.php/nt/article/view/616/610

Pérez Monroy, J. (1997). Aristófanes: el pueblo ateniense frente a la guerra. Nova Tellus, 15, 11-50. Recuperado de https://revistas-filologicas.unam. $\mathrm{mx} /$ nouatellus/index.php/nt/article/view/638/632 
Plácido, D. (2012). Aristófanes como fuente de la historia social. Acarnienses, 1-42. Pecia Complutense, 9(17), 1-13. Recuperado de http://biblioteca.ucm. es/pecia/52309.php

Rodríguez Adrados, F. (1984). Tucídides. Historia de la guerra del Peloponeso I. Madrid: Hernando.

Rodríguez Adrados, F. (1985). Tucídides. Historia de la guerra del Peloponeso III. Madrid: Hernando.

Schere, M. J. (2011). La representación del campesino en la comedia Caballeros de Aristófanes. En C. Ames (ed.), Terceras Jornadas Nacionales de Historia. Segundas Jornadas Internacionales de Historia (pp. 335-345). Córdoba: Universidad Nacional de Córdoba. 